\title{
Effect of transducer flushness on measured surface pressure fluctuations in flight
}

\author{
B.M. Efimtsov ${ }^{*}$, A.Yu. Golubev ${ }^{\dagger}$, V.B. Kuznetsov* \\ TsAGI, 107005 Moscow, Russia \\ S.A. Rizzi ${ }^{\S}$ \\ NASA Langley Research Center, Hampton VA 23681, USA \\ A.O. Andersson ${ }^{* *}$, R.G. Rackl ${ }^{\dagger \dagger}$ \\ Boeing, Seattle WA 98124, USA \\ and \\ E. V. Andrianov \\ Tupolev, 111250 Moscow, Russia
}

\begin{abstract}
The procedure for investigating the effect of deviation from flush mounting of pressure transducers on the exterior of Tu-144LL in flight is described. Experimental data in the machnumber range $0.58-2.0$ are presented for distortion of the measured wall-pressure fluctuation spectra of the turbulent boundary layer by recessed and protruding transducers. The results of flight experiments are compared with data of wind tunnel experiments [1]. The distortion of measured turbulent boundary layer wall pressure fluctuations caused by transducer-surface deviation from the surrounding surface as a function of dimensionless parameters is predicted and presented on the basis of dimensional analysis.
\end{abstract}

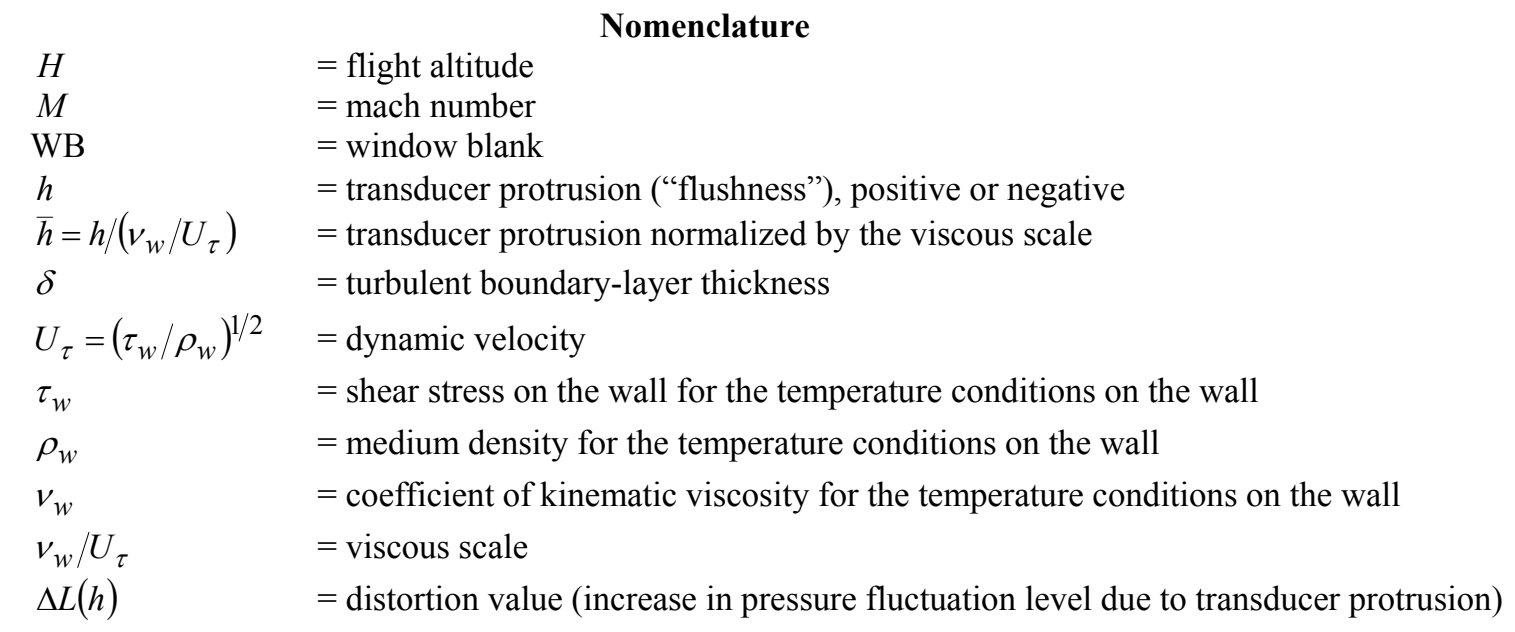

\footnotetext{
${ }^{*}$ Chief of the Structural Acoustic Department, Acoustic Division, 17 Radio St.

${ }^{\dagger}$ Research engineer, Structural Acoustic Department, Acoustic Division, 17 Radio St.

* Research engineer, Structural Acoustic Department, Acoustic Division, 17 Radio St.

$\S$ Aerospace Engineer, AIAA Associate Fellow

${ }^{* *}$ Technical Fellow, Fluid Mechanics \& Acoustics, PO Box 3707, MC 67-ML

†Principal engineer, Fluid Mechanics \& Acoustics, PO Box 3707, MC 67-ML
} 


$$
\begin{array}{ll}
f & =\text { frequency } \\
\omega=2 \pi f & =\text { circular frequency } \\
R e_{\tau}=\delta U_{\tau} / v_{w} & =\text { Reynolds number }=S h_{1} / S h \\
S h=\omega v_{w} / U_{\tau}^{2} & =\text { Strouhal number for the characteristic inertial scale } \delta \\
S h_{1}=\omega \delta / U_{\tau} & =\text { Strouhal number for the characteristic viscous scale } v_{w} / U_{\tau}
\end{array}
$$

\section{Introduction}

Turbulent wall-pressure fluctuations on the exterior surface are the main sources of noise inside high-speed passenger aircraft. Characteristics of these fields, random in space and time, which are required for noise prediction and reduction, can only be obtained from experiments. This is due to the fact that theoretical evaluation of wallturbulence fields is not expected in the near future.

One of the central methodological questions to be solved before making valid experimental measurements of turbulent wall pressure-fluctuation fields is the mounting of transducers on a surface in flow. Experience from experimental research indicates that even a very small $(\sim 0.01 \mathrm{~mm})$ deviation of the sensitive element of the transducer from the surface leads to noticeable distortion of the measured pressure-fluctuation spectra of the turbulent boundary layer. However, this experience applies only to pressure transducers that can be mounted with their sensitive elements flush with the surface. In recent years transducers with sensitive elements under protective screens are usually used for measurement of turbulent wall pressure fluctuations of gas flows. Such transducers (type Kulite XCS-190-15D) were selected for an extensive program of experimental investigations of wall pressure fluctuations of the turbulent boundary layer on $\mathrm{Tu}-144 \mathrm{LL}$ supersonic flying laboratory.

The external cylindrical part of this transducer, where the sensitive element with a protective screen is placed, has a diameter of $\sim 3.9 \mathrm{~mm}$. The sensitive element is recessed and covered with a protective screen forming an air cavity connected with the exterior through small holes in the screen, set in a circle of $\sim 3 \mathrm{~mm}$ diameter with the center on the transducer axis.

With the available experience it seemed impossible to evaluate how measurements of the pressure fluctuations using the XCS-190-15D transducer installation with its protective screen would deviate from those measured with a flush-mounted transducer. This is the reason tests of transducer XCS-190-15D were performed in the TsAGI wind tunnel $\mathrm{T}-125$ at subsonic $(\mathrm{M}=0.5,0.78)$ and supersonic $(\mathrm{M}=1.5,2.0,2.5)$ flow velocities before the Tu-144 flight experiments, see Ref. 1.

The transducer tests obtained pressure-fluctuation measurements on a smooth wall of the wind tunnel test section at different positions of its protective screen: exactly flush-mounted with the wall and with different deviations (h) from this position within $\pm 0.1 \mathrm{~mm}$. A negative $\mathrm{h}$ denotes transducer recess and positive protrusion.

The T-125 wind-tunnel experiments ${ }^{1}$ allowed controlled variations of the protective-screen position of the transducer relative to the flow surface, with direct evaluation of the distortions of the measured turbulent wall pressure fluctuations. Definite recommendations could be made on installation of pressure transducers on the Tu-144LL and on control of their position relative to the measurement surface.

However, when the transducers were installed on the Tu-144LL, it appeared impossible to completely realize the recommendations developed from the wind-tunnel tests. Therefore the experimental data on wall pressure fluctuations of the turbulent boundary layer, obtained on Tu-144LL with the XCS-190-15D transducers were to some degree distorted due to the deviation from flush-mounting of the protective screens. For the transducers set at different points on the Tu-144LL, direct measurements showed significant differences in protective-screen positions relative to the surrounding external surface.

Two urgent tasks became evident: evaluation of the validity of pressure-fluctuation measurements on the Tu144LL surface and to correct for distortions, if possible, based on the experimental data obtained in the wind tunnel. However, it is difficult to justify direct use of the wind-tunnel results for this purpose, since they have been obtained under conditions different from those realized in flight:

First, the wind-tunnel data correspond to smaller Reynolds numbers, and the effect of this on the recorded pressure-fluctuation distortions due to the transducer installation has not yet been studied.

Second, temperature conditions of pressure transducer operation in wind tunnel and in flight differ substantially. In the T-125 wind tunnel the temperature of the test-section wall is practically independent of operating regime. The temperature on the external aircraft surface changes significantly both with altitude and flight mach number. Difference in heat-expansion coefficients of different materials of the transducer environment (window blank, 
insulating boss and the transducer itself) under flight conditions can lead to changes in the position of the sensitive element relative to the wall.

Third, the acoustic interference in the measurements of the pressure-fluctuation aerodynamic field in the windtunnel test section ${ }^{1}$ is significantly different from the acoustic interference on the aircraft surface. The pressure transducer signal due to acoustic excitation depends only weakly (in comparison with the aerodynamic pressurefluctuation effect) on small position changes relative to the flow surface. Therefore the acoustic interference can mask the effect of transducer installation in different ways in the wind tunnel and on the aircraft surface.

The most serious reason preventing the use of the experimental data obtained in T-125 directly for evaluating a validity of pressure-fluctuation measurement results on Tu-144LL, however, is the lack of information from the wind tunnel in the Mach-number range $0.78<\mathrm{M}<1.5$. This is the main range of Mach numbers of current and advanced high-velocity passenger airplanes.

All the above considerations combined to setting the task and making the experimental investigations of transducer protrusion and recess effects in measurements of turbulent wall-pressure fluctuations directly on the Tu-144LL.

\section{Procedure of experimental investigations}

Three areas on the starboard side of Tu-144LL were used for the experimental flight research concerning the effect of deviation from transducer flush mounting ${ }^{2}$. Figure 1 indicates the center of the 11th window (WB2 point 2.1) located at a distance of $25.9 \mathrm{~m}$ from the nose of the aircraft, the center of the 16th window (WB5 point 5.1) at a distance of $33.5 \mathrm{~m}$, and the center of the 26th window (WB6 point 6.1) at a distance of $43.2 \mathrm{~m}$. Three single transducers of type Kulite XCS-190-15D were used.

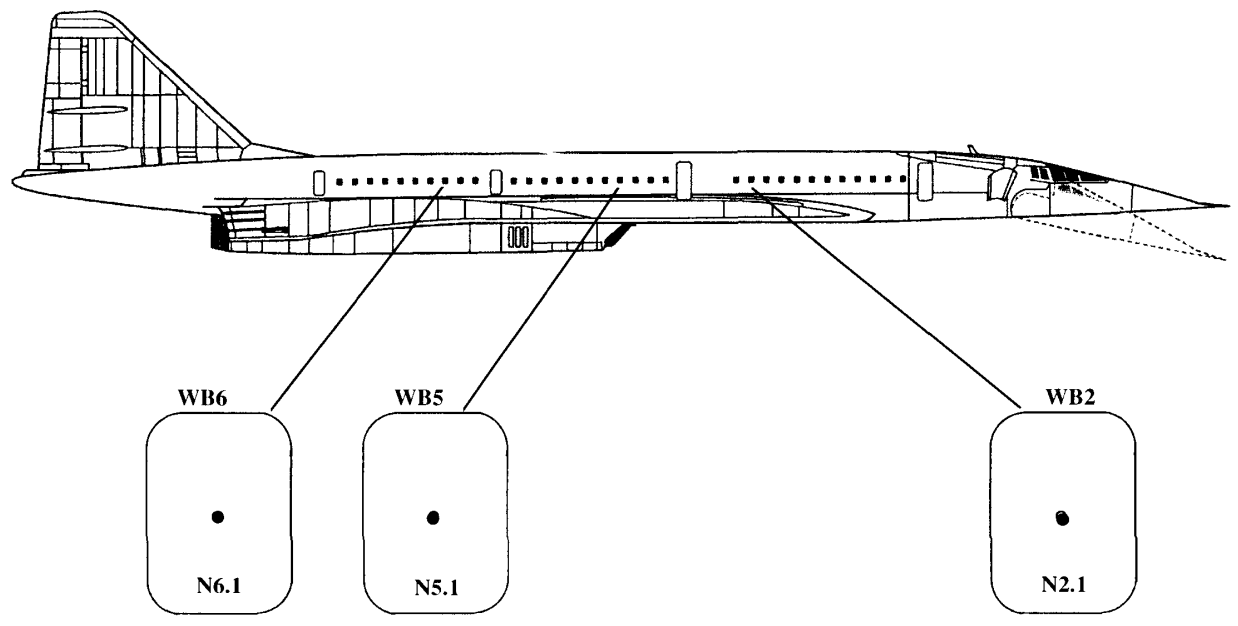

Figure 1. Location of pressure transducers on the starboard side of Tu-144LL

The position of the protective screen of the transducers' sensitive element relative to the aircraft surface could be varied in the range $-0.05 \leq \mathrm{h} \leq 0.05 \mathrm{~mm}$ in $0.01 \mathrm{~mm}$ steps with the device shown in Figure 2, which is similar to the device used in the T-125 wind-tunnel experiment ${ }^{1}$. During preparations for the flight experiments a repeatability study of the transducer displacement with this device was carried out, see Table 1. 


\begin{tabular}{|r|r|r|r|}
\hline $\begin{array}{c}\text { Nominal } \\
\mathbf{h} \\
\mathbf{1 0} \mathbf{- 3} \mathbf{m m}\end{array}$ & \multicolumn{1}{|c|}{$\mathbf{N 6 . 1}$} & N5.1 & N2.1 \\
\hline 0 & 1 & 0 & -0.5 \\
\hline 50 & 52 & 48 & 44.5 \\
\hline 10 & 5 & 5 & 13.5 \\
\hline 0 & -6 & -6 & -4.5 \\
\hline-10 & -19 & -14 & -16.5 \\
\hline-50 & -61 & -50 & -60.5 \\
\hline-10 & -20 & -14 & -18.5 \\
\hline 0 & -8 & -5 & -8.5 \\
\hline 10 & 5 & 3 & 1.5 \\
\hline 50 & 51 & 45 & 43.5 \\
\hline
\end{tabular}

Table 1. Repeatability of transducer displacements ${ }^{2}$.

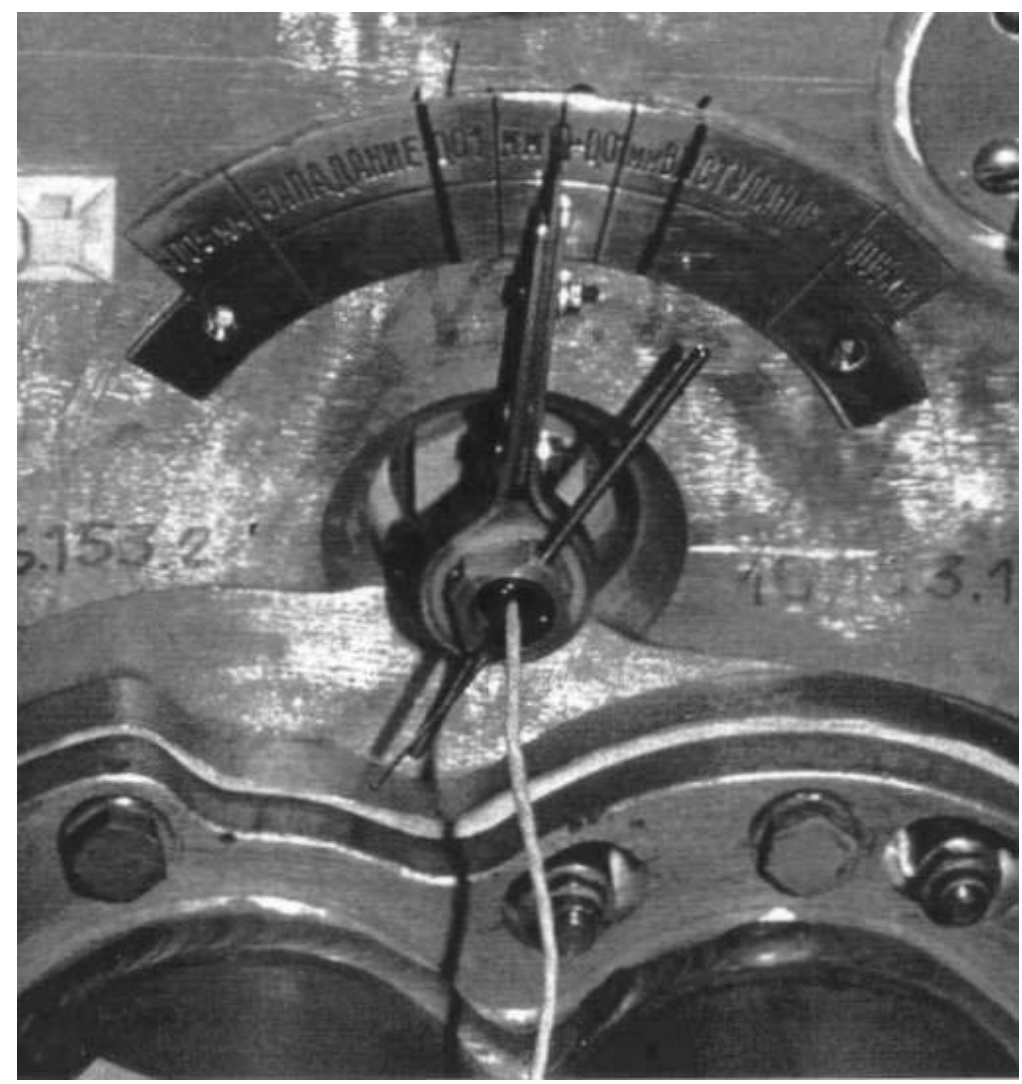

Figure 2. Device for moving the transducer from the flush-mounted position. 
Satisfactory repeatability of limiting transducer protrusion $(\mathrm{h}=0.05 \mathrm{~mm})$ can be noted. However, for recessed transducers, at points 2.1 and 6.1 , the real position appeared to be $\mathrm{h} \approx-0.06 \mathrm{~mm}$ rather than the nominal limiting position $\mathrm{h}=-0.05 \mathrm{~mm}$. Furthermore, with repeated transducer displacements to position $\mathrm{h}=0$, a certain shift in the recess direction was observed.

Directly before the flights, measurements were made of the deviation of the protective-screen position relative to the surrounding surfaces for all the pressure transducers. For this purpose a reference point was selected on the butt end of each transducer's insulating boss, and measurements made to other points, see Figure 3.

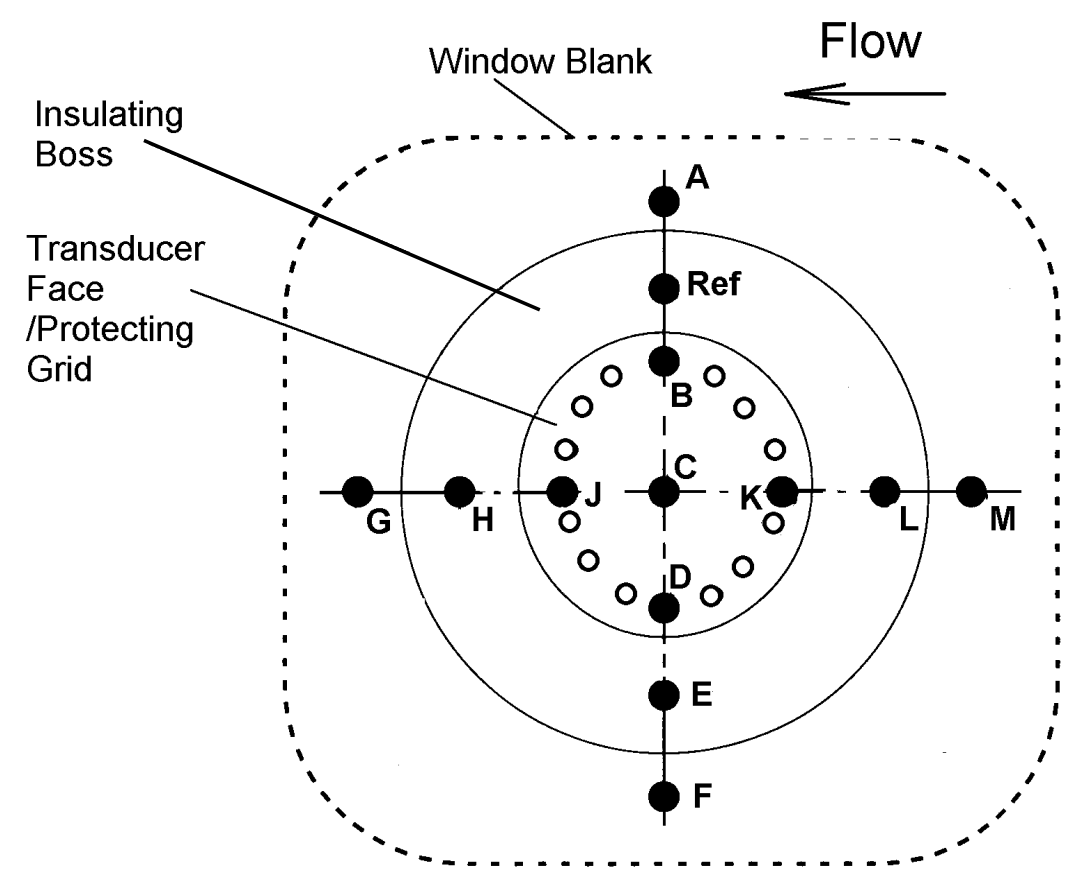

Figure 3. Control points for determining positions of pressure transducer and insulating boss.

Five points were located directly on the protective screen of the transducer, four points (including the reference point) on the insulating-boss butt end, and four points on the window blank. The results of these measurements for transducers 2.1, 5.1 and 6.1 relative to point $\mathrm{M}$ are summarized in Figure 4. Analysis of these measurements indicate that the reference position of transducers 2.1, 5.1 and 6.1 relative to the surrounding surfaces directly before the flight experiment cannot be treated as $\mathrm{h}=0$.

The deviations for point 5.1 are particularly large. The leading edge (relative to the flow) of the protective screen of this transducer extends about $0.008 \mathrm{~mm}$ beyond the insulating boss, which extends an additional about $0.018 \mathrm{~mm}$ beyond the surface of the window blank. The trailing-edge of this transducer butt end deviates slightly from the surface of the blank. However, directly behind the trailing-edge of the transducer the butt-end surface extends about $0.029 \mathrm{~mm}$ beyond the insulating boss. The butt end of transducer 5.1 has a downstream inclination since the locations of points $\mathrm{K}$ near the leading-edge and $\mathrm{J}$ near the trailing-edge differ by $0.031 \mathrm{~mm}$. Such significant downstream inclination and deviation of the protective screen of the transducer from the surrounding surface make the experimental data on the studied effect of transducer installation invalid. 

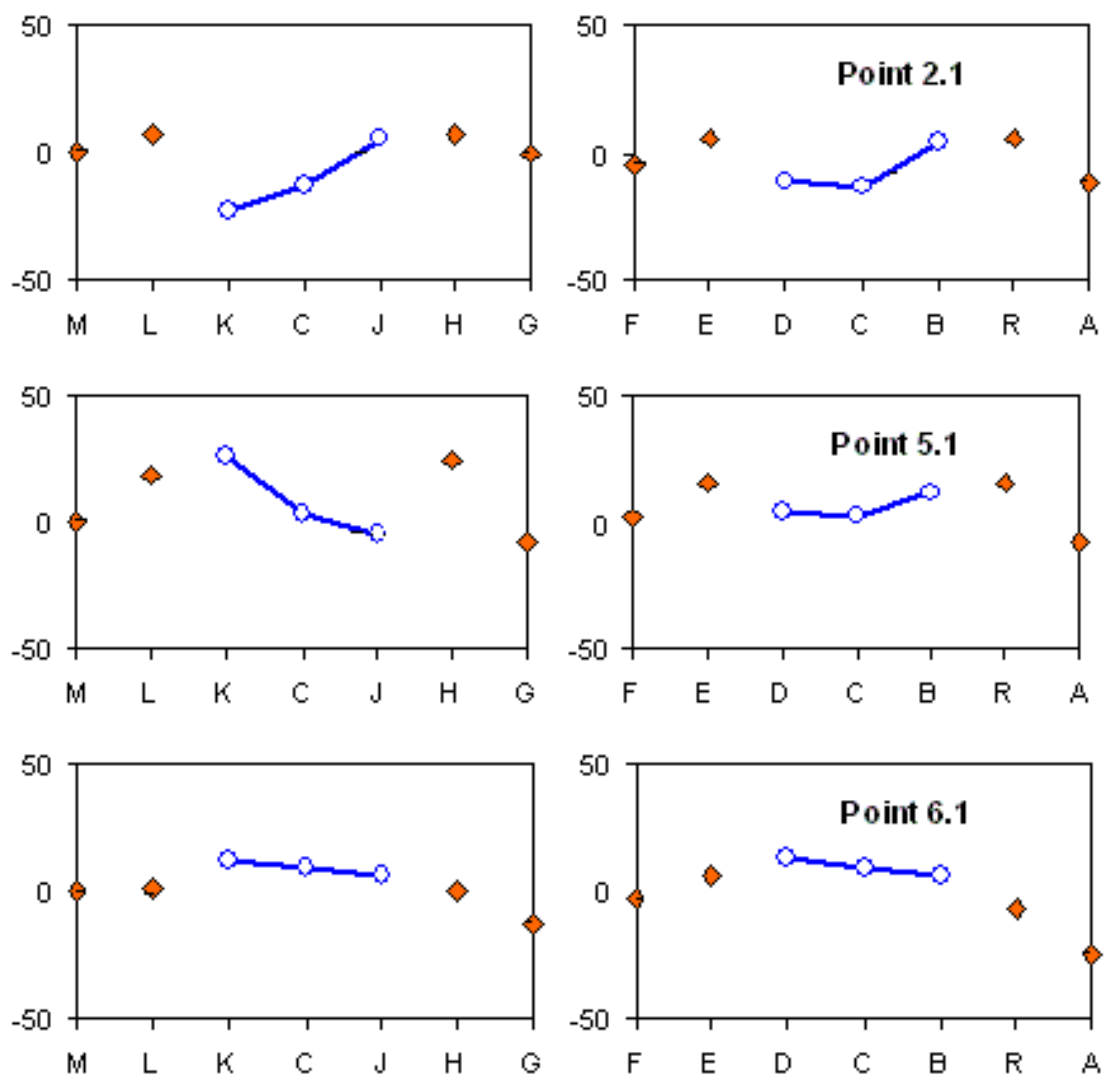

Figure 4. Control points of transducer deviation from surrounding surfaces ( re. point $\mathrm{M}$ )

The leading edge of transducer 2.1 is recessed by $0.030 \mathrm{~mm}$ relative to the surrounding surfaces while its trailing edge is about level with them. Therefore the protective screen has an inclination similar to that of transducer 5.1, but upstream. Such a configuration of deviations of the protective screen of transducer 2.1 from the surrounding surface, the distortions of the measured pressure fluctuations caused can be expected to be less than those of transducer 5.1.

Among the three transducers used for investigation of the effect of the butt end deviations from the surrounding surfaces, transducer 6.1 has the best installation. First, its butt-end leading edge (point K) exceeds the trailing-edge by only $0.006 \mathrm{~mm}$. It is hardly possible that such an inclination of its protective screen can lead to noticeable distortions of the recorded pressure fluctuations. Second, the protective-screen deviation from the butt end surface of the insulating boss is not more than $0.011 \mathrm{~mm}$. Moreover, the part of this surface located far upstream from the transducer practically does not deviate from the surface of the window blank. Therefore it seems reasonable to use mainly the measurement results from transducer 6.1 for evaluating the effect of protective-screen deviations relative to the surrounding surfaces on recorded pressure fluctuations.

The flight measurements made on Tu-144LL for this task covered the mach-number range 0.58 to 2.0. Information on measurement conditions is presented in Table 2, see also Ref. 2. Column 1 gives the flight number (Flight), column 2 the run number (Run), column 3 the mach number (M), column 4 the flight altitude $(\mathrm{H})$, column 5 the transducer deviations from flush with the surface (Flushness, h), column 6 boundary layer thickness $(\delta)$ in each measurement zone (WB 2, WB 6), column 7 dynamic velocity $\left(U_{\tau}\right)$, column 8 the viscous scale $\left(v_{w} / U_{\tau}\right)$ in each measurement zone. For convenience this table also presents some information relating to the experiments in windtunnel T-125. 


\begin{tabular}{|c|c|c|c|c|c|c|c|c|c|c|}
\hline \multirow{3}{*}{$\frac{1}{\text { Flight }}$} & 2 & 3 & 4 & 5 & \multicolumn{2}{|c|}{6} & \multicolumn{2}{|c|}{7} & \multicolumn{2}{|c|}{8} \\
\hline & \multirow[t]{2}{*}{ Run } & \multirow{2}{*}{$\begin{array}{c}\text { Mach } \\
\text { number } \\
\text { M }\end{array}$} & \multirow{2}{*}{$\begin{array}{c}\text { Altitude } \\
\text { H } \\
\text { m } \\
\end{array}$} & \multirow{2}{*}{$\begin{array}{c}\text { Flushness } \\
\mathbf{h} \\
\mathbf{m m}\end{array}$} & \multicolumn{2}{|c|}{$\delta, \mathbf{m}$} & \multicolumn{2}{|c|}{$U_{\tau}, \mathbf{m} / \mathbf{s}$} & \multicolumn{2}{|c|}{$v_{w} / U_{\tau}, \mathbf{m}$} \\
\hline & & & & & WB 2 & $\overline{\text { WB } 6}$ & WB 2 & WB 6 & WB 2 & WB 6 \\
\hline 22 & $73-78$ & 2.0 & $16500-16700$ & \multirow{2}{*}{$\begin{array}{c}-0.05 ;-0.01 ; 0 ; \\
0.01 ; 0.05\end{array}$} & 0.256 & 0.427 & 18.8 & 18.2 & $1.37 \mathrm{E}-5$ & $1.41 \mathrm{E}-5$ \\
\hline 23 & $80-87$ & 2.0 & $16200-16500$ & & 0.256 & 0.427 & 18.8 & 18.2 & $1.37 \mathrm{E}-5$ & $1.41 \mathrm{E}-5$ \\
\hline 24 & $111-115$ & 0.9 & 9000 & \multirow{7}{*}{$\begin{array}{c}-0.05 ;-0.02 ; 0 \\
0.02 ; 0.05\end{array}$} & 0.256 & 0.428 & 8.01 & 7.78 & $5.16 \mathrm{E}-6$ & $5.31 \mathrm{E}-6$ \\
\hline 24 & $116-120$ & 0.58 & 4900 & & 0.256 & 0.428 & 5.38 & 5.23 & $4.55 \mathrm{E}-6$ & $4.68 \mathrm{E}-6$ \\
\hline 24 & $121-125$ & 0.75 & 4900 & & 0.256 & 0.429 & 6.90 & 6.72 & $3.81 \mathrm{E}-6$ & $3.91 \mathrm{E}-6$ \\
\hline 24 & $126-130$ & 0.9 & 9000 & & 0.256 & 0.428 & 8.01 & 7.78 & $5.16 \mathrm{E}-6$ & $5.31 \mathrm{E}-6$ \\
\hline 24 & $131-135$ & 0.58 & 4900 & & 0.256 & 0.428 & 5.38 & 5.23 & $4.55 \mathrm{E}-6$ & $4.68 \mathrm{E}-6$ \\
\hline 25 & $138-142$ & 1.8 & 15500 & & 0.256 & 0.427 & 16.6 & 16.1 & $1.08 \mathrm{E}-5$ & $1.12 \mathrm{E}-5$ \\
\hline 25 & $143-147$ & 1.8 & 16400 & & 0.256 & 0.427 & 16.6 & 16.1 & $1.11 \mathrm{E}-5$ & $1.15 \mathrm{E}-5$ \\
\hline 26 & $159-163$ & 2.0 & 16000 & \multirow{2}{*}{$\begin{array}{c}-0.05 ;-0.02 ; 0 ; 0 ; \\
0.02 ; 0.05\end{array}$} & 0.256 & 0.427 & 18.7 & 18.1 & $1.27 \mathrm{E}-5$ & $1.31 \mathrm{E}-5$ \\
\hline 26 & $164-168$ & 2.0 & 16700 & & 0.256 & 0.427 & 18.9 & 18.3 & $1.47 \mathrm{E}-5$ & $1.52 \mathrm{E}-5$ \\
\hline \multirow{5}{*}{\multicolumn{2}{|c|}{ Wind tunnel }} & 0.5 & - & \multirow{5}{*}{$\begin{array}{c}-0.10 ;-0.05 ; \\
-0.02 ;-0.01 ; 0 \\
0.01 ; 0.02 ; \\
0.05 ; 0.10\end{array}$} & \multicolumn{2}{|c|}{0.016} & \multicolumn{2}{|c|}{6.5} & \multicolumn{2}{|c|}{$3.62 \mathrm{E}-06$} \\
\hline & & 0.78 & - & & \multicolumn{2}{|c|}{0.018} & \multicolumn{2}{|c|}{9.8} & \multicolumn{2}{|c|}{$2.35 \mathrm{E}-06$} \\
\hline & & 1.5 & - & & \multicolumn{2}{|c|}{0.0225} & \multicolumn{2}{|c|}{16.8} & \multicolumn{2}{|c|}{$4.91 \mathrm{E}-06$} \\
\hline & & 2 & - & & \multicolumn{2}{|c|}{0.0273} & \multicolumn{2}{|c|}{19.5} & \multirow{2}{*}{\multicolumn{2}{|c|}{$7.69 \mathrm{E}-06$}} \\
\hline & & 2.5 & - & & \multicolumn{2}{|c|}{0.0288} & \multicolumn{2}{|c|}{21} & & \\
\hline
\end{tabular}

Table 2. Measurement conditions during Tu-144LL flight test and corresponding wind-tunnel tests

As can be seen in Table 2 the measurements at $\mathrm{M}=0.58, \mathrm{M}=0.9$ and $\mathrm{M}=1.8$ were performed twice and at $\mathrm{M}=2.0$ four times. Variations of flushness $\mathrm{h}$ were made in discrete steps: $\mathrm{h}=-0.05,-0.02,0.00,+0.02,+0.05 \mathrm{~mm}$ (for all mach numbers except $\mathrm{M}=2.0$ ) and $\mathrm{h}=-0.05,-0.02,-0.01,0.00,+0.01,+0.02,+0.05 \mathrm{~mm}$ (for $\mathrm{M}=2.0$ ). A more detailed indication of flushness settings for a particular run number is provided in Ref. 2.

Preliminary analysis of the measurement results was carried out in order to solve methodological questions, including evaluation of their validity for the subsequent analysis. In particular, narrow-band spectral analysis of the pressure fluctuations established that variation of the transducer flushness did not lead to the appearance of narrowband or discrete components in the spectra. The variations of transducer position were accompanied by pressurefluctuation intensity variations over broad frequency bands. This allowed the subsequent analysis of pressure fluctuation spectra to be made only in $1 / 3$-octave frequency bands.

Interference from acoustic waves substantially distorts the studied effects of transducer flushness on pressurefluctuation measurements. The acoustic interference masks the real effect of transducer installation, especially in the case when the installation results in reduced pressure-fluctuation intensity.

As an example, Figure 5 shows an almost complete loss of the effect of transducer protrusion and recess in the pressure fluctuation spectra in the vicinity of $31.5 \mathrm{~Hz}$, where the acoustic interference is significantly higher than the turbulent boundary layer pressure fluctuations. An analysis of neighboring transducers (not shown) were highly coherent at that frequency, indicating an acoustic disturbance. Acoustic interference from the power plant is what determines the frequency dependence of distortions $\Delta L(h)$ in the region below $100 \mathrm{~Hz}$ at $\mathrm{M}=0.9$ (Figure 6). Here and below, $\Delta L(h)$ is the difference between the pressure-fluctuation levels in 1/3-octave frequency bands recorded when the transducer deviates $(\mathrm{h})$ from its reference position and the levels recorded at its reference position. This quantity is subsequently referred to as the distortion value. 


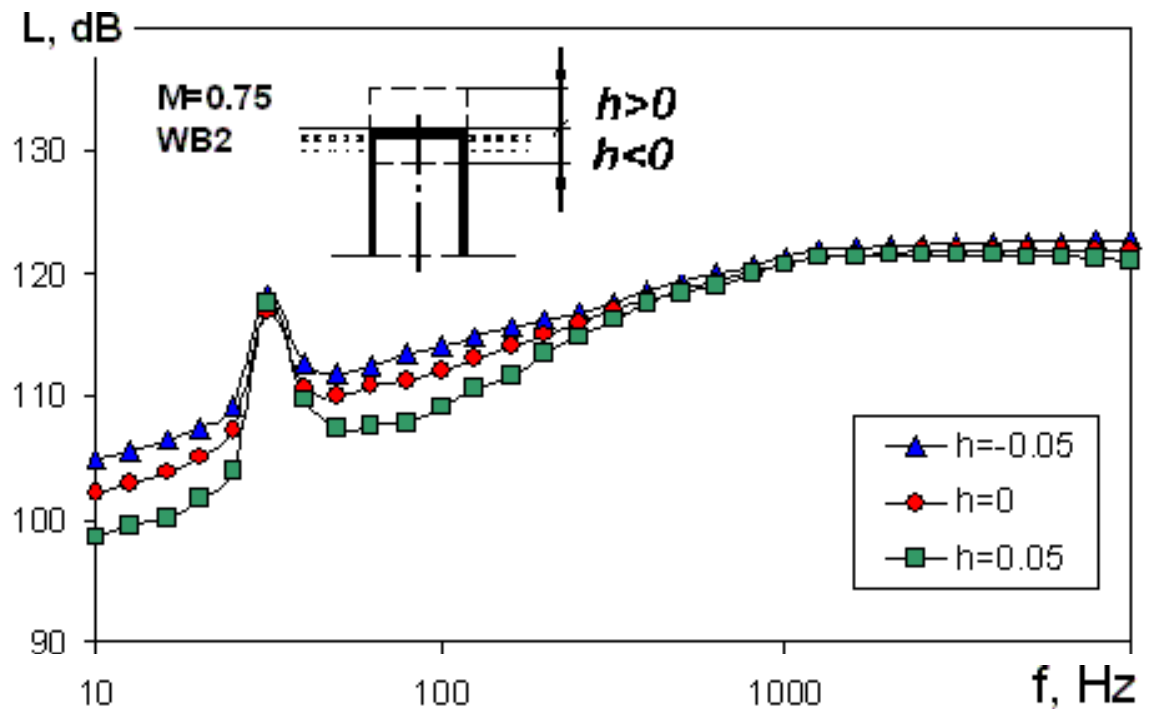

Figure 5. Effect of transducer flushness deviation for pressure fluctuation spectra in zone WB2 at $\mathrm{M}=0.75$.

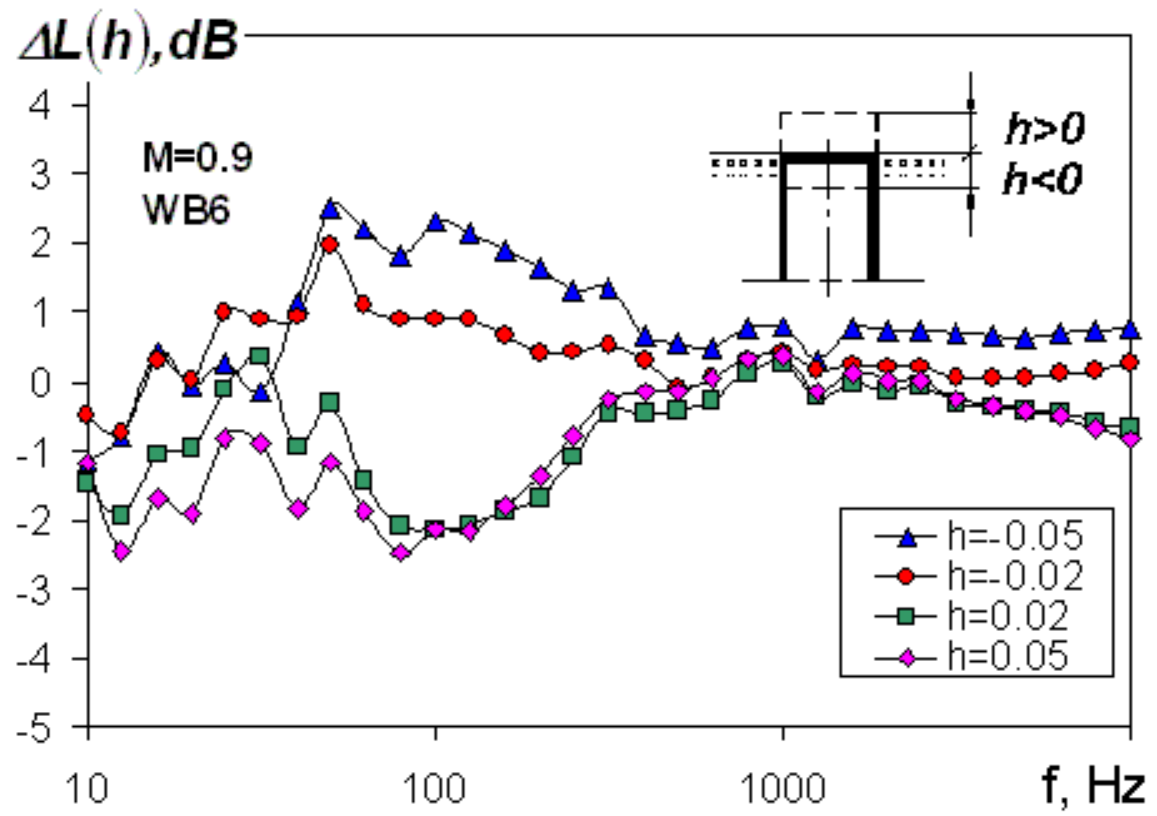

Figure 6. Effect of transducer flushness deviation in zone WB6 at M=0.9. 


\section{Results of experimental investigations}

The measured pressure fluctuation spectra from the Tu-144LL experiments are in qualitative agreement with the data obtained in the T-125 wind-tunnel experiments. When the transducer deviates in the direction of negative values (recessed), the recorded pressure fluctuations increase over the whole spectrum with the largest effect in the lowfrequency region (Figure 7). A substantially smaller effect is observed in the high-frequency region. The minimum variations of the recorded pressure fluctuations are observed in the intermediate frequency region from 0.5 to $2.0 \mathrm{kHz}$.

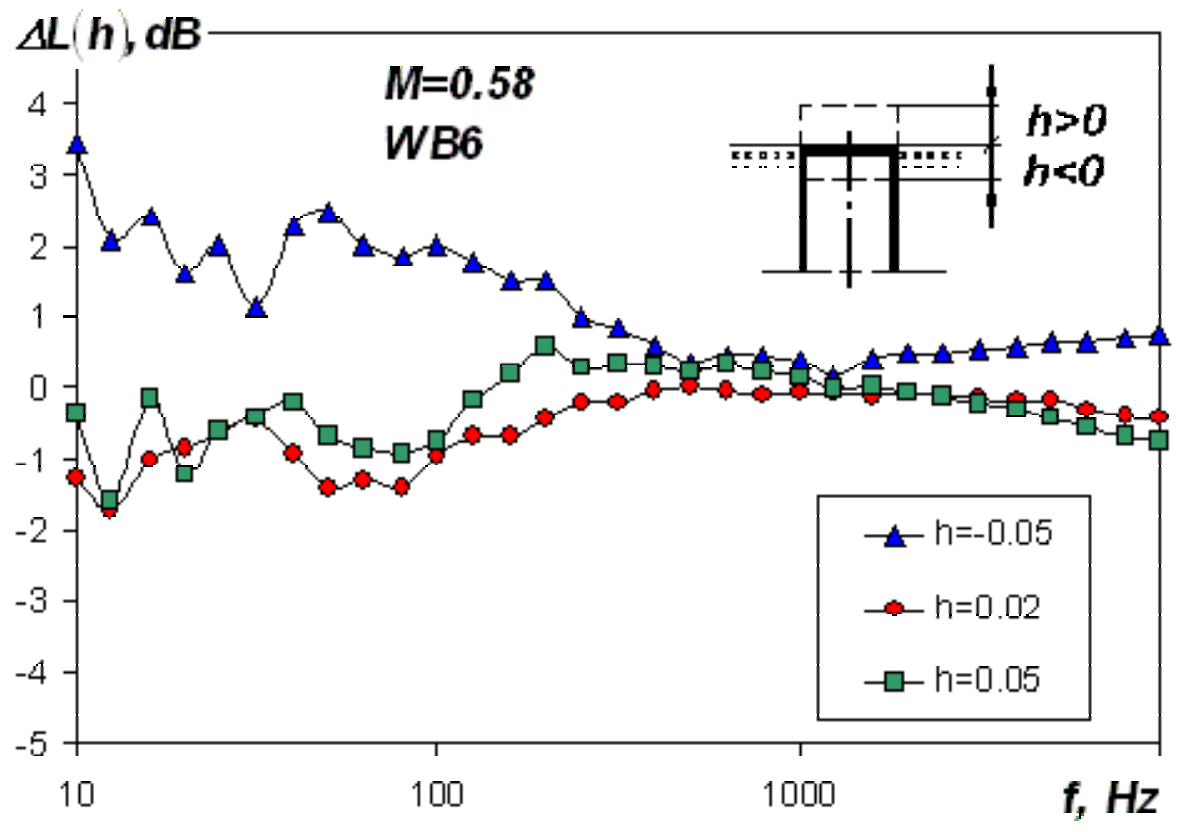

Figure 7. Effect of transducer flushness deviation in zone WB6 at $\mathrm{M}=0.58$

When the transducer deviates in the direction of positive values of $h$ (protrudes from the surrounding surface), the recorded pressure fluctuations decrease with increase in $\mathrm{h}$, but only down to a definite value. Subsequent increase of $\mathrm{h}$ is followed by an increase of pressure fluctuations measured by the transducer. Due to the limited range of $h$ values in the flight experiment, only some tendency of this qualitative variation of the effect is seen. A wind-tunnel experiment ${ }^{1}$ at $\mathrm{h}=0.1 \mathrm{~mm}$ has shown that this tendency transforms into a clearly expressed pattern of increased pressure-fluctuation recordings as $h$ increases.

It should be noted here that at positive values of $h$, the largest effect is observed in the low-frequency region. When the frequency exceeds $100 \mathrm{~Hz}$, the distortion of the measured pressure-fluctuation spectrum decreases substantially, achieves minimum values $\mid \Delta L(h)$ in the frequency range $0.5 \leq f \leq 2.0 \mathrm{kHz}$ and then rises smoothly.

The flight-experiment data in Figure 7 relate to $M=0.58$. However they differ only slightly from those shown in Figure 6 obtained at $\mathrm{M}=0.9$. The essential difference between the two cases below $100 \mathrm{~Hz}$ is mainly due to acoustic interference from the aircraft power plant.

All the results presented above for $\Delta L(h)$ were obtained on Tu-144LL from transducer 6.1, which had a reference position closer to flush with the surrounding surfaces than transducer 2.1. Figure 8 illustrates a comparison of $\Delta L(h)$ obtained with the use of transducers 6.1 and 2.1 at $\mathrm{M}=0.58$. A difference of up to $1 \mathrm{~dB}$ between the experimental data obtained with different transducers in the frequency range $\mathrm{f}<250 \mathrm{~Hz}$ is clearly seen. At frequencies $\mathrm{f}>250 \mathrm{~Hz}$ this difference is negligible. The observed difference can be due not only to different reference positions of these transducers but also to different thickness of the turbulent boundary layer in their installation zones. As seen in Table 2, the boundary-layer thickness at transducer 6.1 is 1.5 times larger than that at transducer 2.1

.The turbulent boundary layer thickness is still greater (by a factor 10 to 30) at transducer 6.1 on Tu-144LL than that on the T-125 wind-tunnel test section wall, where the effect of transducer deviation from the flush position on the measured fluctuations was investigated. However, the observed distortions of the turbulent wall pressure-fluctuation spectra at identical deviations of the transducers are not more than 2dB (Figure 9). 


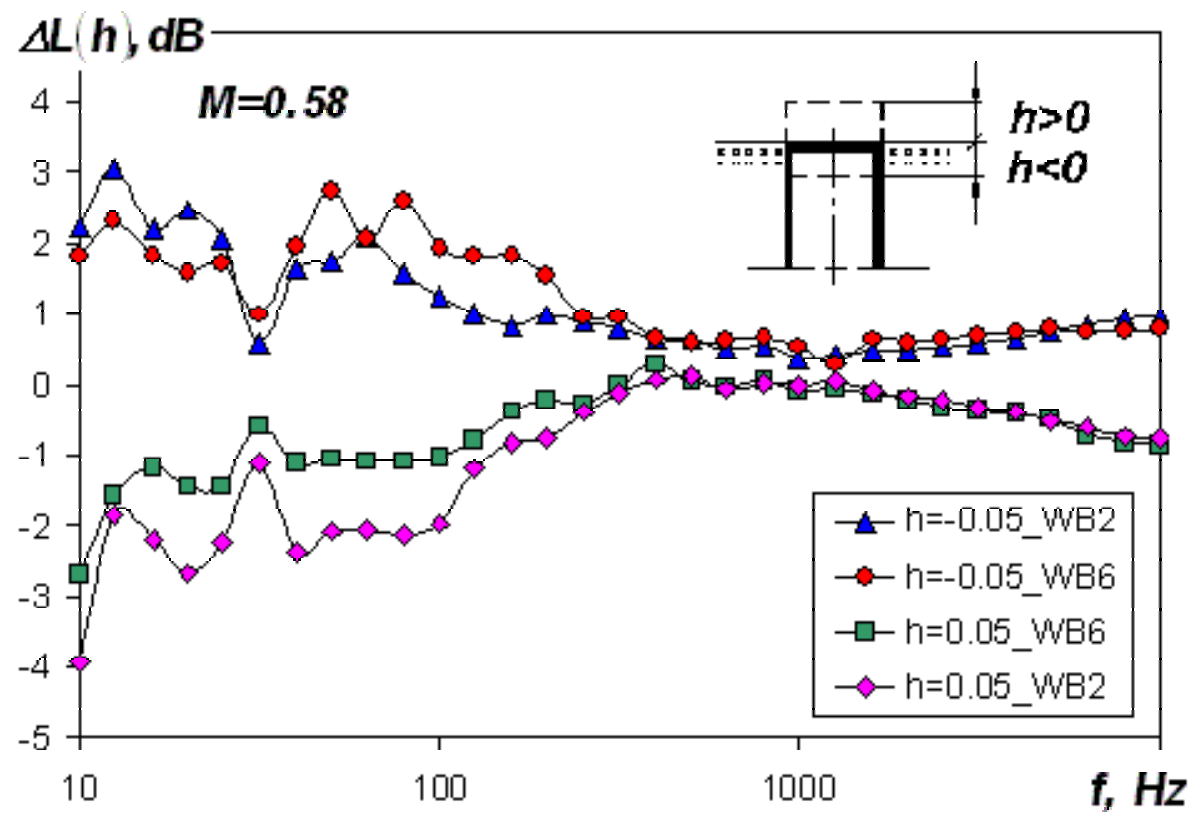

Figure 8. Effect of transducer flushness deviation in zones WB2 and WB6 at $\mathrm{M}=0.58$

Explanation of these phenomena and generalization of the data from wind tunnel and flight experiments can only be made using similarity theory. Results of analysis of the similarity criteria of the turbulent wall pressure-fluctuation spectra are presented in Ref. 3. For turbulent boundary layer wall pressure fluctuations on a smooth surface with zero gradient of the mean pressure, analysis and generalization of wind-tunnel and flight experiments on the basis of the similarity theory and the theory of random fields established ${ }^{3}$ that the main

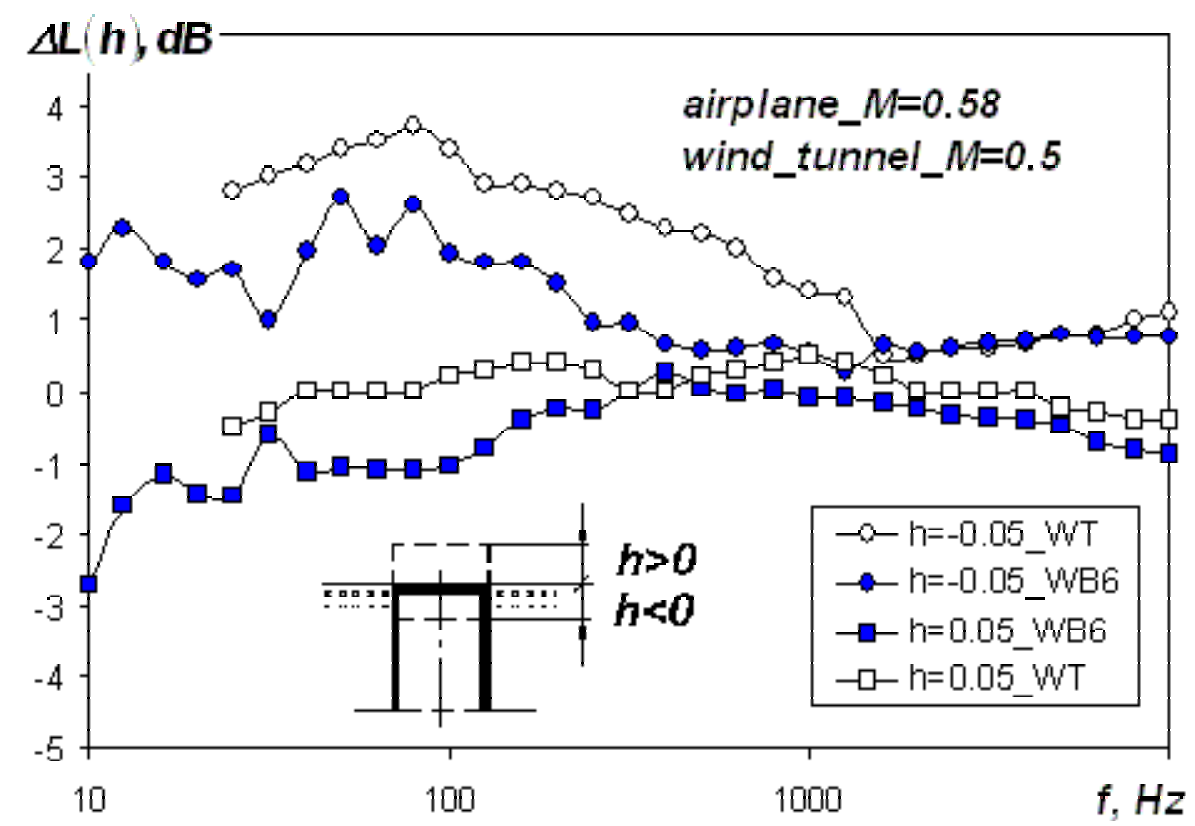

Figure 9. Comparative evaluation of effect of transducer flushness deviation from measurements on the flight laboratory Tu-144LL and the T-125 wind tunnel 
similarity criteria are Strouhal number for the characteristic inertial scale $\delta\left(S h_{1}=\omega \delta / U_{\tau}\right)$, and Strouhal number for the characteristic viscous scale $v_{w} U_{\tau}\left(S h=\omega v_{w} / U_{\tau}^{2}\right)$, since the Reynolds number $\left(\operatorname{Re}_{\tau}=\delta U_{\tau} / v_{w}\right)$ relates the two via $\operatorname{Re}_{\tau}=S h_{1} / S h$.

Here $\omega=2 \pi f$ is the circular frequency, $\delta$ the turbulent boundary-layer thickness, $U_{\tau}=\left(\tau_{w} / \rho_{w}\right)^{1 / 2}$ the dynamic velocity, $\tau_{w}$ the shear stress on the wall, $\rho_{w}$ the medium density; $v_{w}$ the coefficient of kinematic viscosity for the temperature conditions directly on the wall.

It was shown in Ref. 3 that the turbulent wall pressure fluctuations were determined mainly by two phenomena. One of them is localized directly at the wall (in a viscous sub-layer). The determining parameters for the pressure fluctuations generated by this phenomenon are to be considered dynamic velocity and viscous linear scale $v_{w} / U_{\tau}$. The second one is localized at some distance from the wall, in the part of the velocity profile in the boundary layer which can be treated as logarithmic. The determining parameters for the pressure fluctuations generated by the second phenomenon are to be considered dynamic velocity and inertial scale $(\delta)$.

The studied effects of transducer deviations from its flush position on the measured pressure fluctuations relate only to small deviations (less than $0.1 \mathrm{~mm}$ ) from the wall. Therefore it can be assumed that these effects relate mainly to phenomena observed directly at the wall (in the viscous sub-layer), where the viscous scale is characteristic. This assumption can be tested with the use of significant-parameter analysis. This procedure, important for dimensional analysis, can be applied to the experimental data obtained in the wind tunnel and on the aircraft.

The case in point here is a comparison between the experimental data obtained at identical values of viscous scale and different values of inertial scale. Figure 10 illustrates such a comparison for the values of $\Delta L(h)$ obtained in the wind tunnel experiments ${ }^{1}$ at $\mathrm{M}=0.5$ and on Tu-144LL at $\mathrm{M}=0.75$ in zone WB 2 for the case $\mathrm{h}=-0.05 \mathrm{~mm}$. The viscousscale values for the flight experiment $\left(v_{w} / U \tau=3.91 \cdot 10^{-6} \mathrm{~m}\right)$ and the wind-tunnel experiment $\left(v_{w} / U \tau=3.62 \cdot 10^{-6} \mathrm{~m}\right)$ are almost identical while the inertial-scale value in the flight experiment $(\delta=0.429 \mathrm{~m})$ is substantially greater (almost by the factor 27) than this value in the wind tunnel $(\delta=0.016 \mathrm{~m})$.

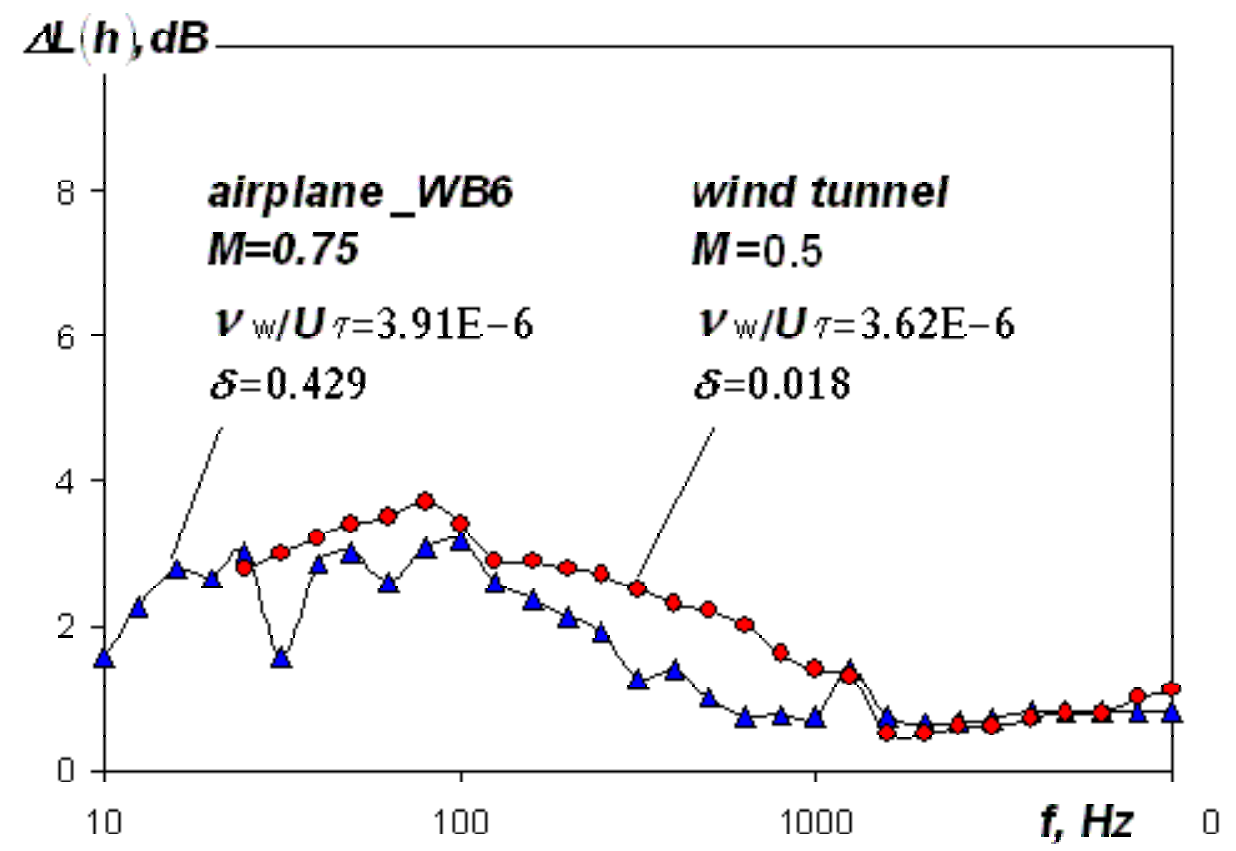

Figure 10. Influence of boundary-layer thickness on transducer recess effect

With such a small difference in $\Delta L(h)$ (commensurate with measurement accuracy) obtained at significantly different values of the boundary layer thickness (more than by the factor 20), one can hardly claim any importance of the inertial scale in the effect of distortion of measured turbulent wall-pressure fluctuations. 
This is the reason the laboratory and flight measurement data in Figure 10 are so similar. This result also makes it possible to state that the observed difference in the experimental flight data obtained in two different zones (Figure 8) is determined not by the boundary layer thickness, but by different reference positions $(+0.05$ and $-0.05 \mathrm{~mm})$ of transducers 2.1 and 6.1 set in these zones.

Since there is no other linear scale than the viscous scale $\left(v_{w} / U_{\tau}\right)$ to influence the studied effect of distortion of the measured turbulent boundary layer wall pressure fluctuations, the viscous scale will be used below in the analysis of experimental results according to similarity theory.

Dimensional analysis makes it possible to present the distortion value of the measured turbulent boundary layer wall pressure fluctuations as a function of dimensionless parameters:

$$
\Delta L(\bar{h})=10 \lg F(S h, \bar{h}, M) .
$$

Here $\bar{h}=h\left(v_{w} U_{\tau}\right)$ is the dimensionless (normalized by the viscous scale) transducer deviation relative to the surrounding surface. $\Delta L(\bar{h})$ can be presented as a function of Strouhal number depending on $\bar{h}$ and $\mathrm{M}$ as parameters, or as a function of $\bar{h}$ depending on $S h$ and M as parameters.

Figure 11 and Figure 12 illustrate a comparison between the experimental data obtained in T-125 and on Tu144LL. Here the representation of $\Delta L(\hbar)$ as a function of Strouhal number is used, with $\bar{h}$ as parameter, for two mach numbers. Figure 11 presents the wind-tunnel data for $\mathrm{M}=0.5$ (at $\bar{h}=-5.5$ and $\bar{h}=-13.1$ ) and in two zones (WB 2 and WB 6) on Tu-144LL at $\mathrm{M}=0.58$ (for $\bar{h}=-11.2$ and $\bar{h}=-10.6$ ).

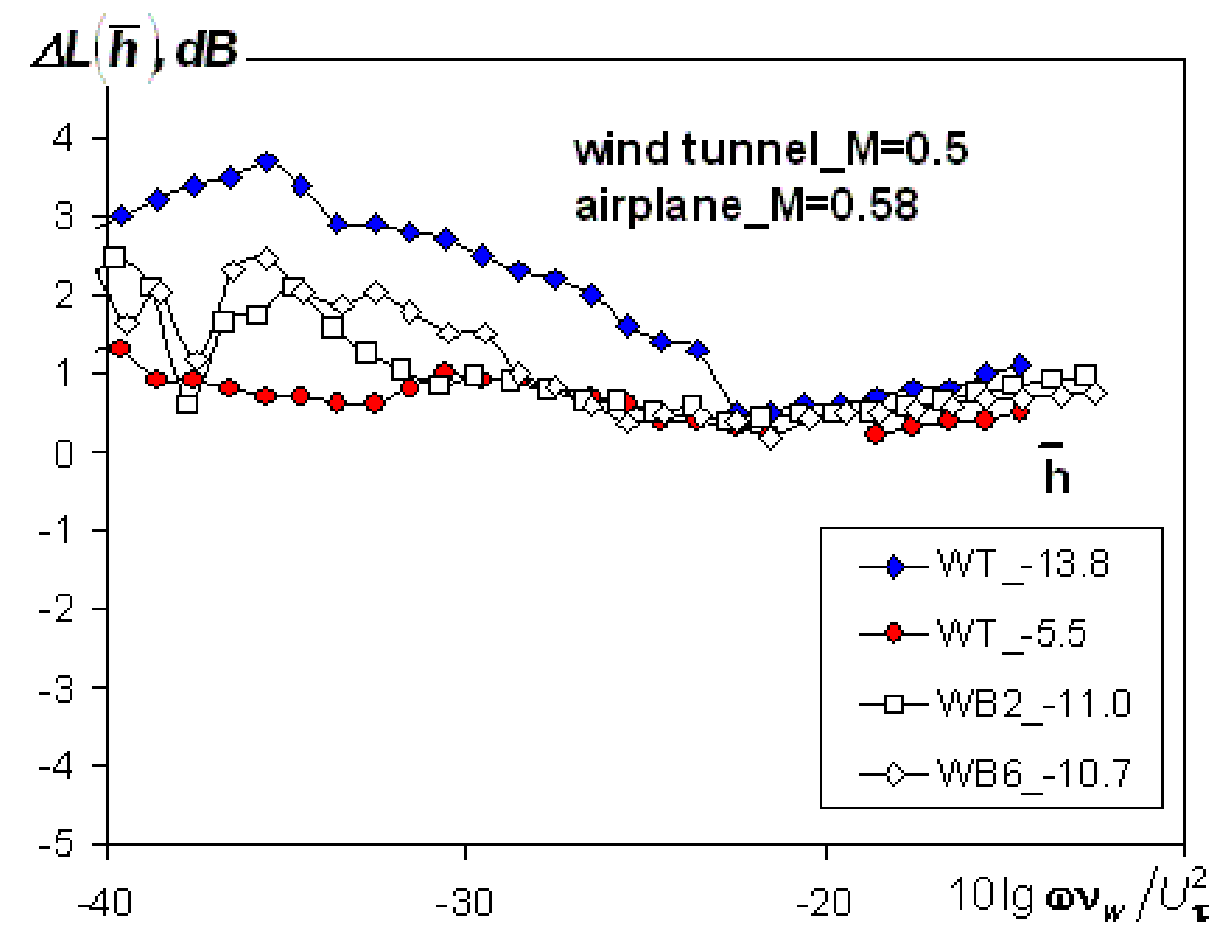

Figure 11. Dimensionless representation of the effect of transducer flushness deviation in the measurements on Tu144LL and in T-125 at low subsonic flow velocity.

The agreement between laboratory and flight results confirms the validity of the similarity criteria used. Similar comparison results follow also from Figure 12, where the data on $\Delta L(\hbar)$ obtained in the wind tunnel at $\mathrm{M}=0.78$ and on Tu-144LL at $\mathrm{M}=0.75$ are presented. The data on $\Delta L(h)$ dependency on Strouhal number at $\mathrm{M}=1.8$ for positive $h$ (protruding transducer) and for negative $\bar{h}$ (transducer recessed relative to the surrounding surfaces) are presented in Figure 13. 


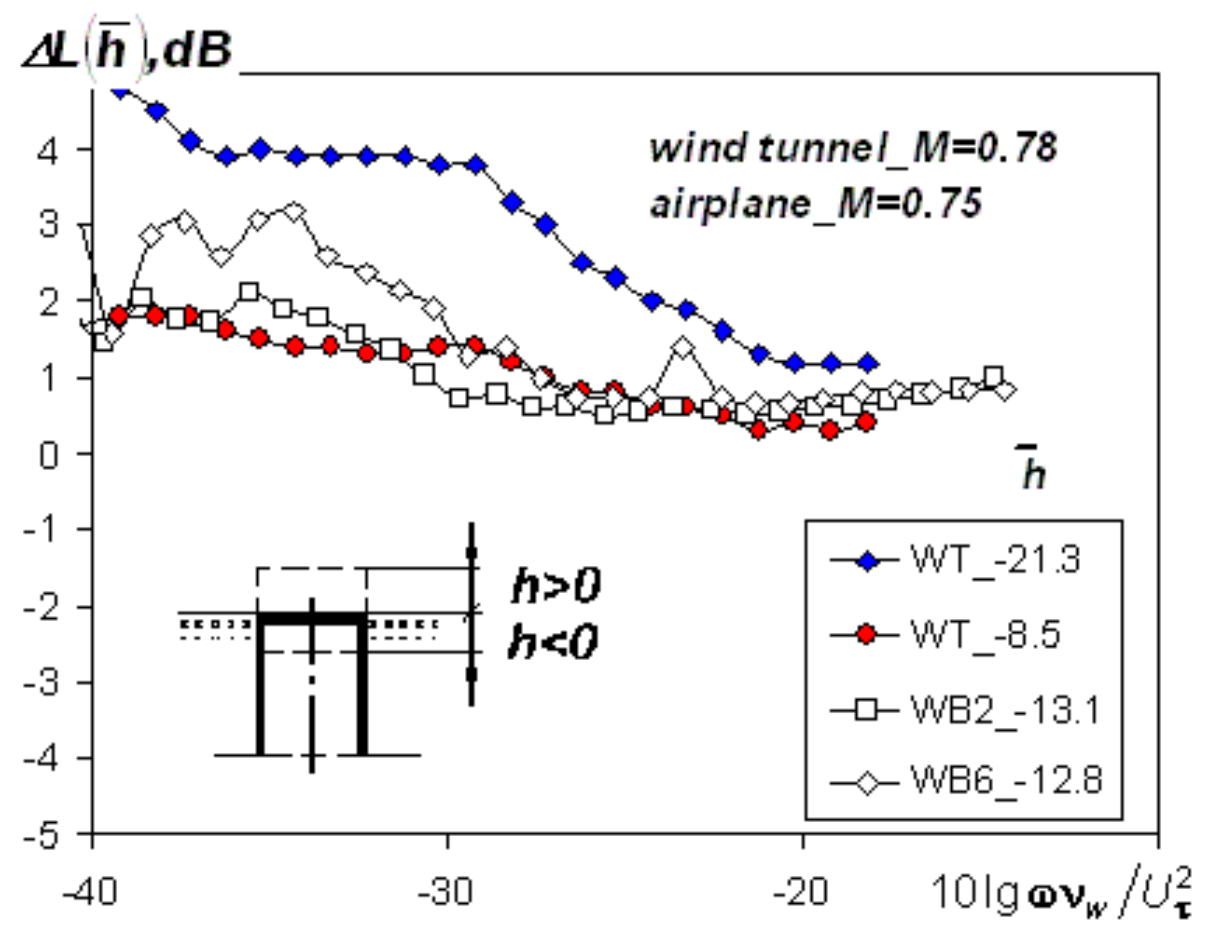

Figure 12. Dimensionless representation of the effect of transducer flushness deviation in the measurements on Tu144LL and in T-125 wind tunnel at $\mathrm{M}=0.75-0.78$

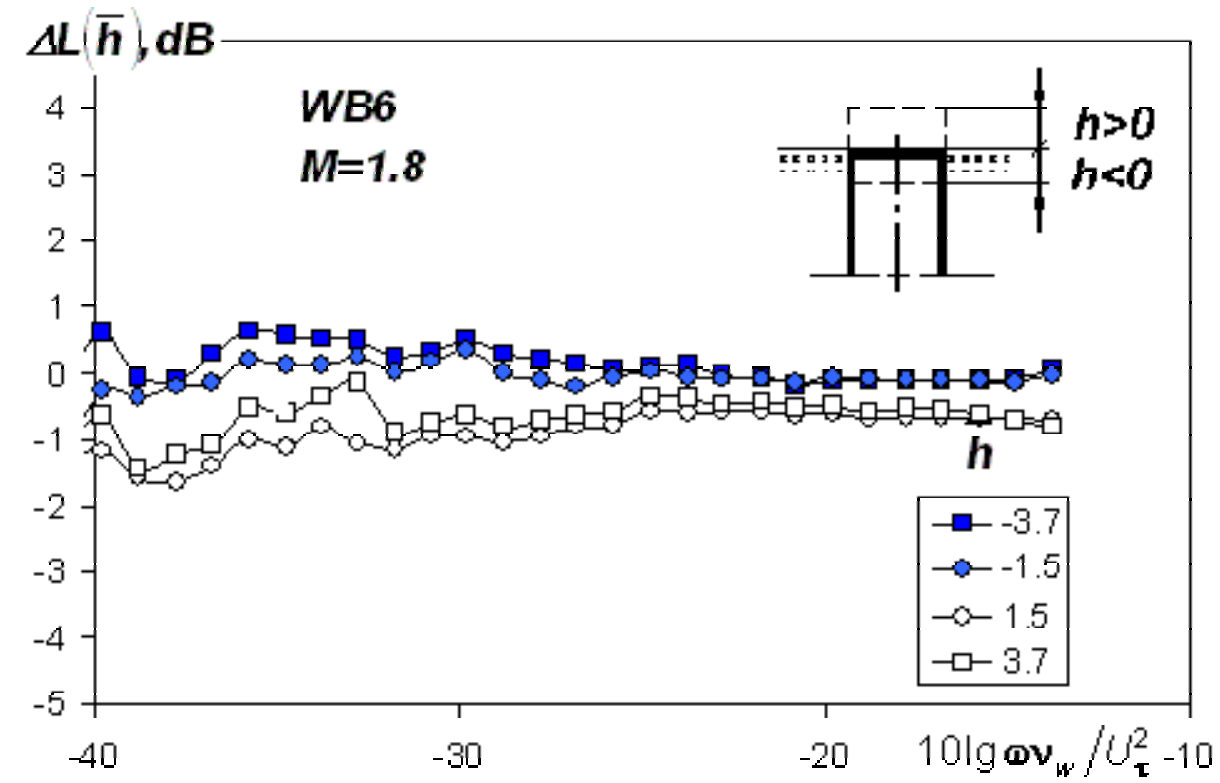

Figure 13. Dimensionless representation of effect of transducer flushness deviation in zone WB6 at M=1.8.

In the following, the value of $\Delta L(\bar{h})$ determined from the flight experiment is presented as the function of the dimensionless value $(h)$ depending on Strouhal and mach numbers as parameters. Figures 14-16 illustrate such a representation for three mach numbers $(\mathrm{M}=0.58 ; 0.9 ; 2.0)$ at the fixed Strouhal number corresponding 
to $10 \lg S h=-34$. This relatively small Strouhal number was taken from the frequency region $(80-100 \mathrm{~Hz})$ where there is no evidence of narrow-band maxima and discrete components, i.e. acoustic interference is unimportant.

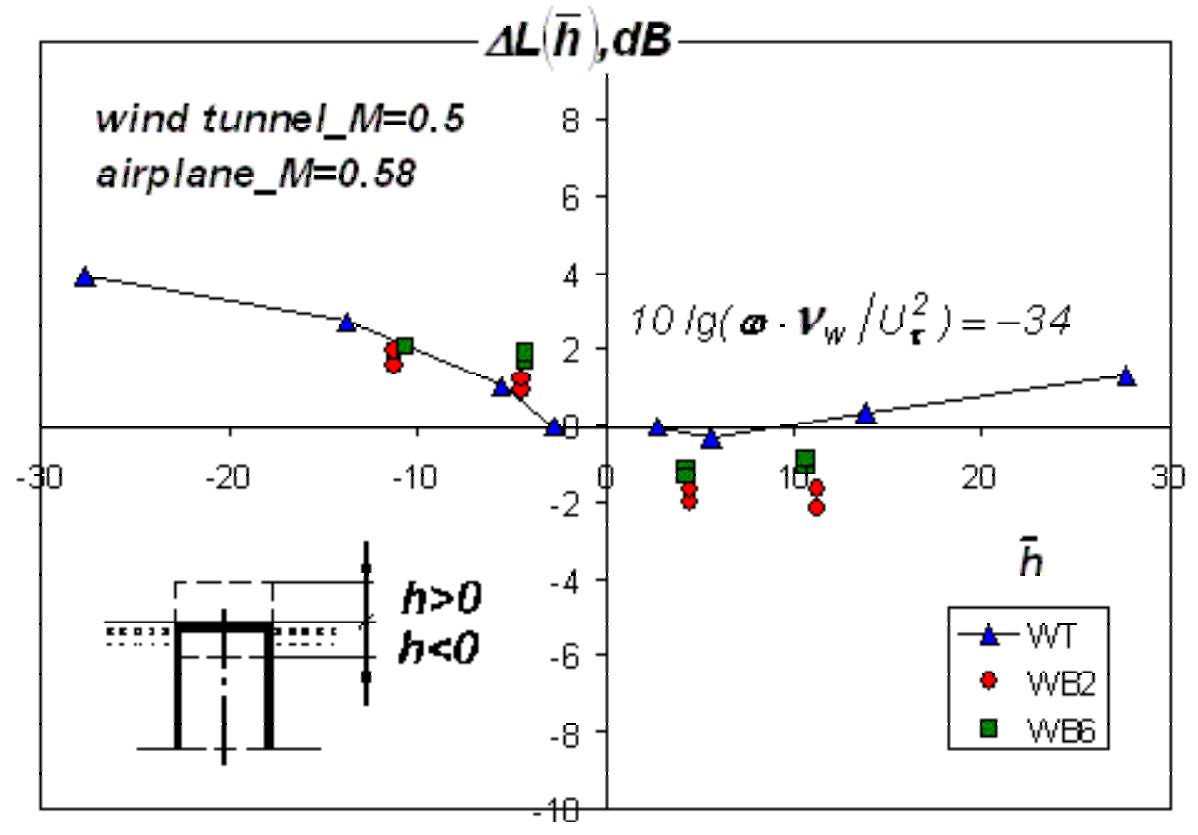

Figure 14. Effect of transducer-flushness deviation in the measurements on Tu-144LL and in T-125 at fixed Strouhal number $(10 \operatorname{lgSh}=-34)$ and low subsonic flow velocity

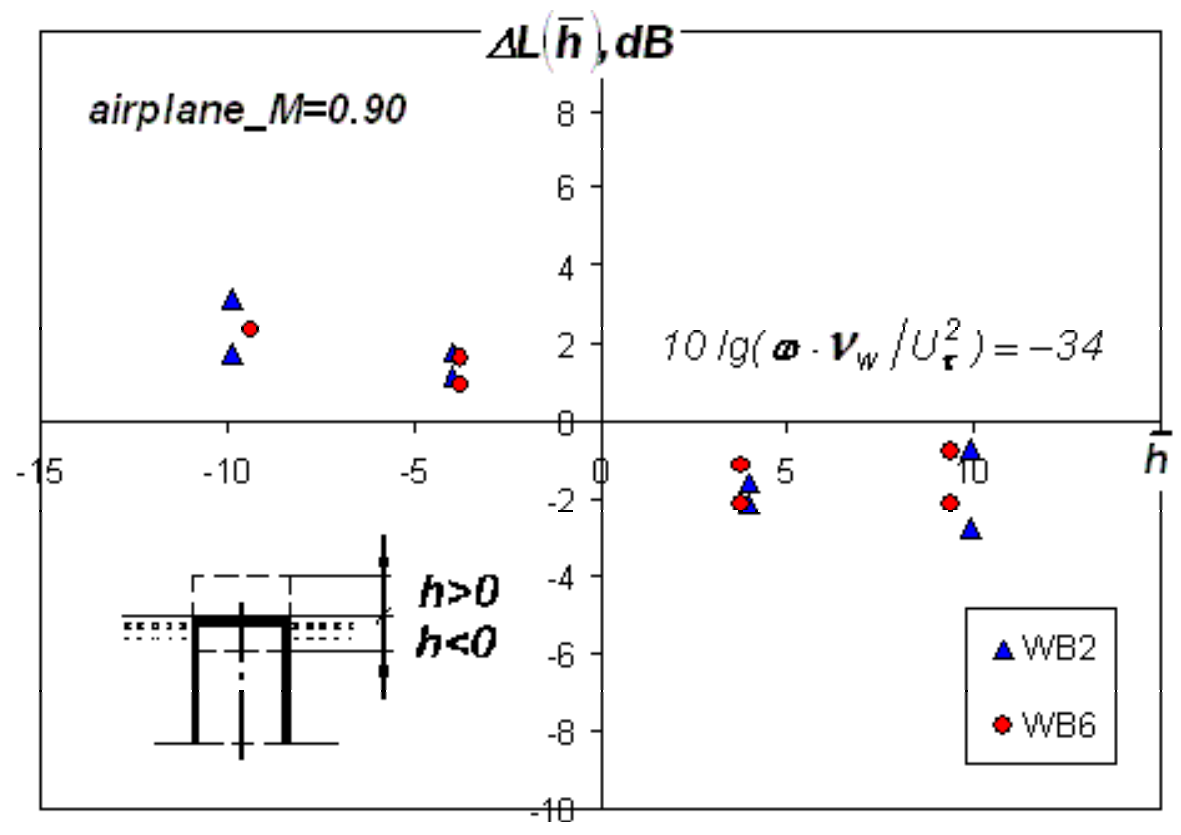

Figure 15. Effect of transducer-flushness deviation in the measurements on Tu-144LL and in T-125 at fixed Strouhal number $(10 \operatorname{lgSh}=-34)$ at $\mathrm{M}=0.9$ 


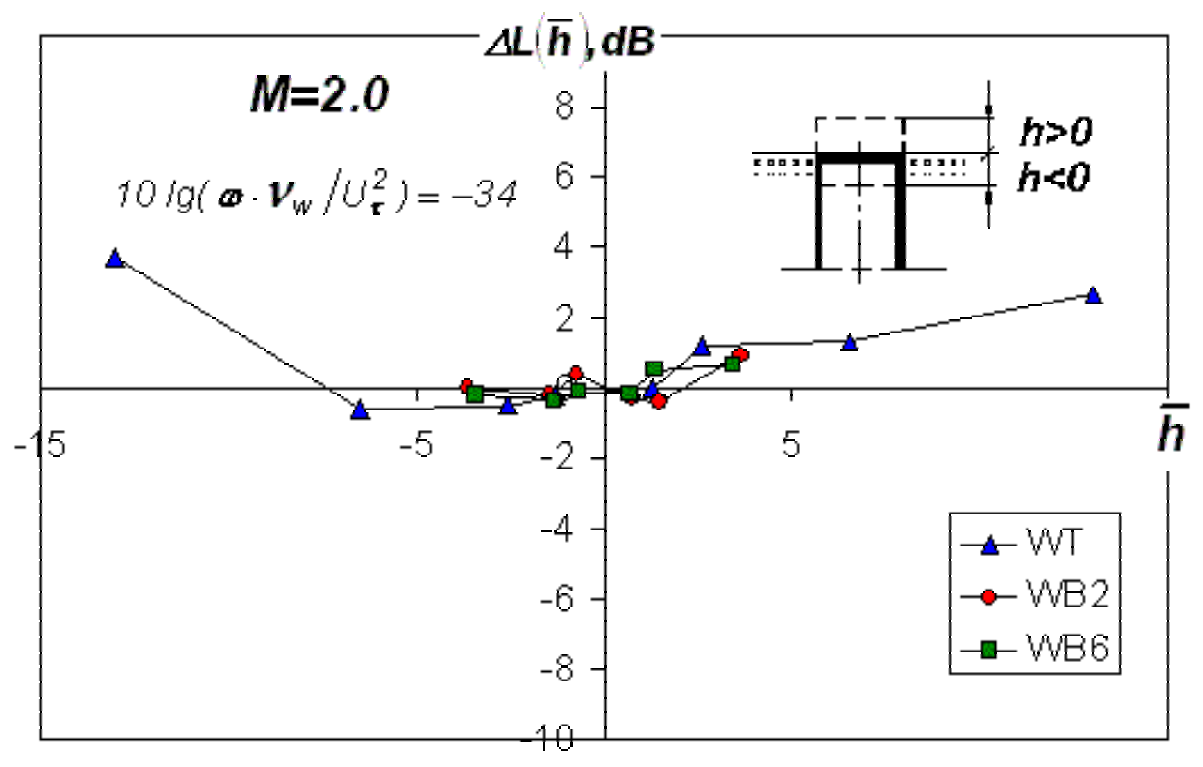

Figure 16. Effect of transducer flushness deviation in the measurements on Tu-144LL and in T-125 at fixed Strouhal number $(10 \operatorname{lgSh}=-34)$ at $\mathrm{M}=2.0$

Figures 14 and 16 also present the results of measurements in the wind tunnel at $\mathrm{M}=0.5$ and $\mathrm{M}=2.0$, respectively. They are in qualitative agreement with the measurements on Tu-144LL.

The dependency of $\Delta L(\bar{h})$ on mach number for small Strouhal numbers can be inferred from the results presented in Figure 17. For $\mathrm{M} \leq 0.9$ there is a slight Mach-number dependence in the character of $\Delta L(\hbar)$, while at $\mathrm{M}=1.8$ and $\mathrm{M} \approx 2.0$ the dependencies $\Delta L(\hbar)$ are practically undistinguishable. The dependencies for supersonic conditions are usually different from those obtained under subsonic conditions both in character and magnitude of $\Delta L(\bar{h})$. The distortions in measurements of turbulent wall pressure fluctuation spectra at $1.8 \leq M \leq 2.0$ are smaller than those observed at $\mathrm{M} \leq 0.9$. 


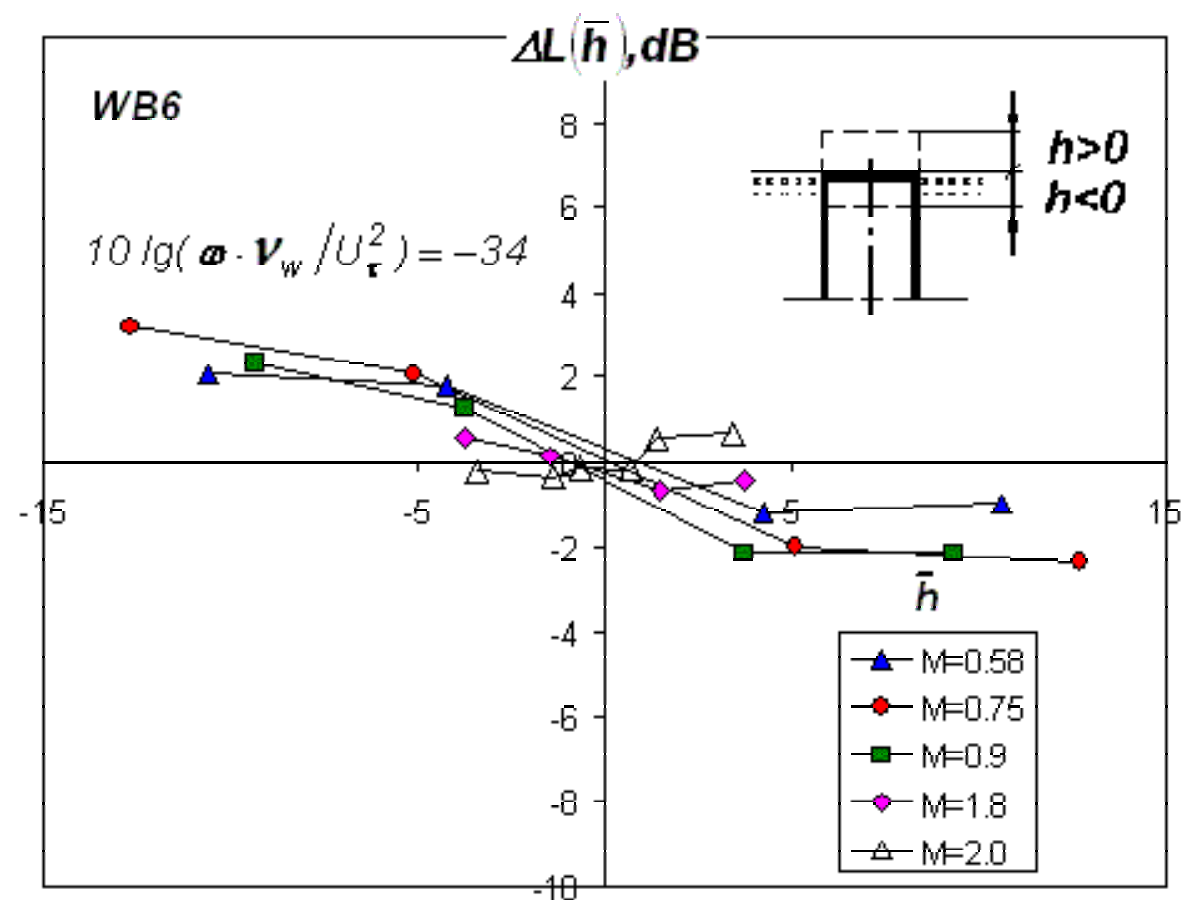

Figure 17. Dimensionless representation of effect of transducer flushness deviation in zone WB6 at fixed Strouhal number $(10 \operatorname{lgSh}=-34)$ at different $\mathrm{M}$

\section{Concluding remarks}

Small deviations from flush mounting of pressure transducers with surrounding flow-grazed surface are accompanied by large distortion of the measured pressure-fluctuation spectra of the turbulent boundary layer. In particular, transducer recess leads to a large increase in the recorded signals. Very small transducer protrusion leads to a reduction of the recorded signals, but further protrusion is accompanied by increased distortion. The frequency dependency of distortions is characterized by decreased distortions when Strouhal number increases for small Sh, and by increased distortions for large Sh. The effect of transducer flushness on measured turbulent wall pressure fluctuations is defined by phenomena localized in the viscous sub layer, i.e. it is defined by the viscous scale $\left(v / U_{\tau}\right)$ and not the inertial scale (boundary layer thickness). This makes it possible to predict the described effect from wind tunnel experiments performed at small values of boundary layer thickness.

\section{References}

1. Efimtsov B.M., Golubev A. Yu., Kuznetsov V.B. "Determination of optimum fluctuation pressure transducer mount configuration and frequency response for Tu-144LL", Report, Contract Boeing-TsAGI, No.101M, 1996.

2. Rizzi, S.A., Rackl, R.G., and Andrianov, E.V., "Flight Test Measurements From The Tu-144LL Structure/Cabin Noise Follow-On Experiment," NASA/TM-2000-209859, February 2000.

3. Efimtsov B.M. "Similarity criteria of spectra of wall pressure fluctuations of the turbulent boundary layer", Akustichesky zhurnal, v.30, No.1, 1984. 